\title{
Integrated Approach to Drilling Project in Unconventional Reservoir Using Reservoir Simulation
}

\author{
Jerzy Stopa ${ }^{1, *}$, Rafał Wiśniowski ${ }^{1}$, Paweł Wojnarowski ${ }^{1}$, \\ Damian Janiga ${ }^{1}$, and Krzysztof Skrzypaszek ${ }^{1}$ \\ ${ }^{1}$ AGH University Science and Technology, Faculty of Drilling, Oil and Gas, \\ A. Mickiewicza Av. 30, 30-059 Krakow, Poland
}

\begin{abstract}
Accumulation and flow mechanisms in unconventional reservoir are different compared to conventional. This requires a special approach of field management with drilling and stimulation treatments as major factor for further production. Integrated approach of unconventional reservoir production optimization assumes coupling drilling project with full scale reservoir simulation for determine best well placement, well length, fracturing treatment design and mid-length distance between wells. Full scale reservoir simulation model emulate a part of polish shale - gas field. The aim of this paper is to establish influence of technical factor for gas production from shale gas field. Due to low reservoir permeability, stimulation treatment should be direct towards maximizing the hydraulic contact. On the basis of production scenarios, 15 stages hydraulic fracturing allows boost gas production over 1.5 times compared to 8 stages. Due to the possible interference of the wells, it is necessary to determine the distance between the horizontal parts of the wells trajectories. In order to determine the distance between the wells allowing to maximize recovery factor of resources in the stimulated zone, a numerical algorithm based on a dynamic model was developed and implemented. Numerical testing and comparative study show that the most favourable arrangement assumes a minimum allowable distance between the wells. This is related to the volume ratio of the drainage zone to the total volume of the stimulated zone. Key words - hydraulic fracturing, shale reservoir, numerical simulation.
\end{abstract}

\section{Introduction}

Hydraulic fracturing in shales formation should be aimed to maximizing hydraulic contact between wells and rock matrix by production network of micro fractures. By increasing the drainage area well performance could be increased over times, however efficient hydraulic treatment process is a complex process in which simultaneous phenomena directly affect the effect and scale, making it difficult to predict the overall project efficiency. Owing to the heterogeneity of reservoir layers, the shape of the fracture can be properly predicted only on the basis of a properly selected fracture model and quality of geological-reservoir

* Corresponding author: stopa@agh.edu.pl 
properties [1]. The complexity of this process causes that the analysis of expected results cannot be done quickly. In this case complex numerical modeling of this operation is very useful as it accounts for geomechanical properties of rocks, varying distribution of stresses, gradient of geostatic and reservoir pressure as well as filtration parameters connected with exploitation model of the reservoir [2]. In the case of tight or shale gas reservoirs the 3D numerical models have to be involved where from total stress in reservoir fracture dimension can be calculated [3-5]. Fracturing treatment design comes to three technological parameters: slurry injection rates and density and viscosity of used fluids. Advanced fracturing models are based on stress balance, energy balance, fluid flow and transport of the proppant, as well as equation of fracturing fluid filtration to the rock matrix. Fracturing models based on 3D geometry enable modeling of an irregular set of fractures, the shape of which is conditioned by local properties of reservoir. Process efficiency can be evaluated by applying simple analytical solutions or reservoir simulations, performed as an individual calculation process based only on the fracturing results. This solution is limited by the lack of full integration of the project with the predicted production, which is necessary for optimization processes.

Mechanisms of accumulation and flow of hydrocarbons in unconventional reservoirs are different in comparison to conventional reservoirs. The phenomena characteristic for unconventional gas deposits can be classified as [6]:

- natural fracture,

- sorption / desorption,

- non-stationary flows in nano-Darcy permeation matrix,

- modelling complex geometries of natural and induced gaps,

- high flow velocities in fractures,

- rock compaction,

- exposure wells with complex topology.

Integration of complex fracture geometry with mechanism of accumulation and flow can be obtain by coupling fracturing simulation with numerical flow simulation.

\section{Methodology}

\subsection{Near wellbore simulation model}

\subsubsection{Static model}

Numerical model of near well zone of shale reservoir using hydraulic fracturing requires the development of an accurate characteristic of the interval to be tested. It is necessary to construct a model of the interesting zone integrating geomechanical and flow properties. On the basis of geological data in the form of records of geophysical logs, a general model of the canopies zone has been developed covering the interval 2600-2915 m TVD. The local geological model used to simulate the fracturing process and their efficiency covers an area of $5 \mathrm{~km}^{2}(2.5 \times 2 \mathrm{~km})$ and has been discretized with a grid of $25 \times 25 \mathrm{~m}$ blocks. The distribution natural permeability in numerical simulation model is shown in Figure 1.

\subsubsection{Dynamic model}

The static geological model was supplemented with the fluid model as well as the initial and boundary conditions. Reservoir temperature is $85^{\circ} \mathrm{C}$ and is full field by methane. PVT fluid properties are calculated from the Peng-Robinson equation [7]. Desorption curve was described by Langmuir [8]. The static model assumes the existence of a double porosity 
system, where a mass storage matrix and fracture network coexists. The dynamic model assumes a hydrodynamic balance between those systems. The matrix does not have primary permeability and is saturated with natural gas. Natural fractures have very low permeability and are saturated with water. Due to the low permeability of the fractures, it is possible to extract the reservoir water during operation.

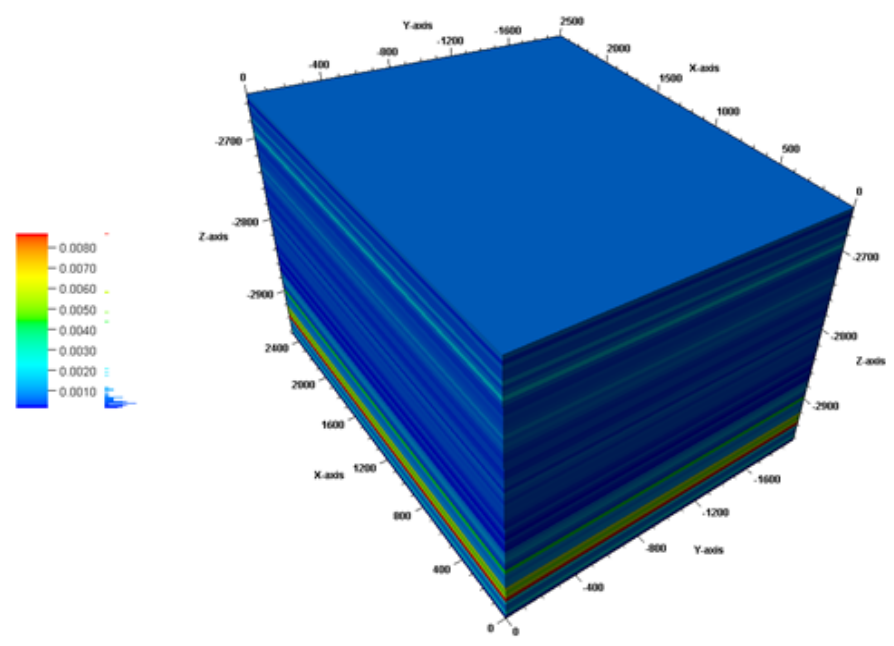

Fig. 1. Nature permeability distribution in near well simulation model

\subsection{Well trajectory}

The trajectory of the wellbore proposed in this study assumes the vertical section to a depth of $2623.5 \mathrm{~m}$ and then begins to curve with a fixed DLS of $6^{\circ} / 30 \mathrm{~m}$. The trajectory assumes the end of the curvature at a depth of $2910 \mathrm{~m}$ (TVD) with a final inclination of $90^{\circ}$. Final borehole length (MD) is $4450 \mathrm{~m}$, of which approximately $1400 \mathrm{~m}$ is the horizontal section in which fracture will be performed. Well trajectory is presented in Figure 2.

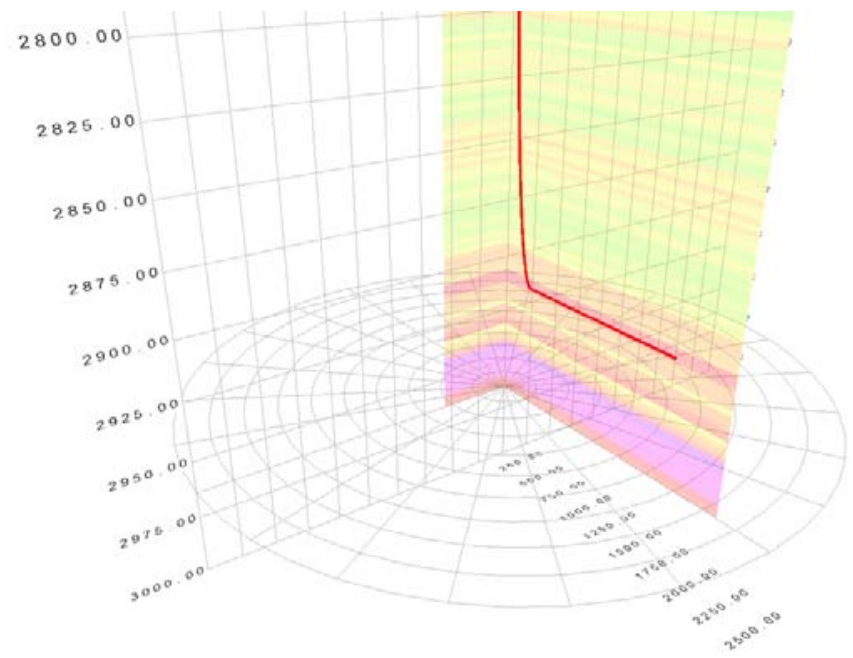

Fig. 2. Borehole trajectories in the reservoir zone model 


\subsection{Technological model of multi-stage fracturing}

\subsubsection{Selection of perforation locations for multi-stage hydraulic fracturing in horizontal wells based on the model of the reservoir zone}

The purpose of modeling the hydraulic fracturing process is to achieve the best hydraulic contact of the well with the reservoir by fracturing. One of the key decisions in this process is the location of the perforation clusters, taking into account the reservoir conditions. The distance between perforation clusters should take into account the minimal impact on the stressing area of the adjacent fractures. The direct effect on the fracture have: optimal selection of the productivity and amount of proppant in each stage of fracturing, reservoir thickness and its brittleness, as well as determination of the fracture propagation limits. For the assumed well trajectory, two variants were analysed: 8 clusters of perforations (equaled $150 \mathrm{~m}$ ) and 15 perforation clusters, (equaling $75 \mathrm{~m}$ ). Clusters of 8 perforation is presented in Figure 3.

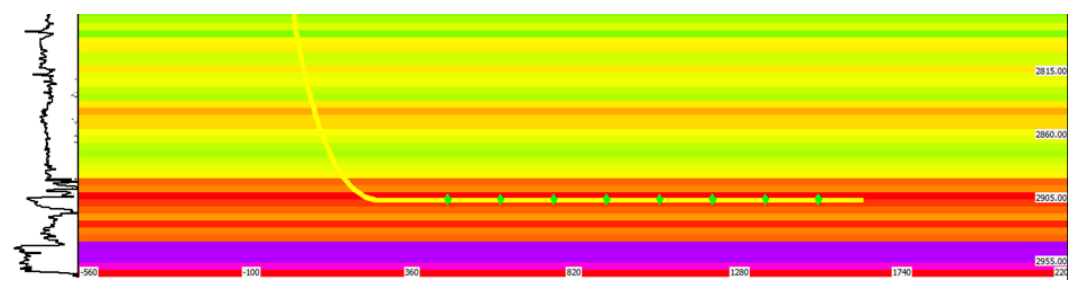

Fig. 3. Localization of the perforation in the second variant comprising 8 clusters

Performing the hydraulic fracture in the first variant minimizes the adverse effect of the individual stages on the overall effect of the treatment [9-10]. The distance between the individual clusters in the second variant allows the use of Zipper Frac [11]. For the proposed perforation locations, the influence of applied treatment liquid on the geometry of the resulting gap and the amount and type of applied proppant material was analyzed on the hydraulic conductivity of the resulting.

\subsubsection{An integrated model of shale reservoir and SRV zones}

Due to the superposition of phenomena occurring during the exploitation of shales stimulated by hydraulic fracturing, fast analysis of the effectiveness of analytical methods is impossible. In this case turns out to be a comprehensive numerical modeling of exploitation by integrating the results of fracture treatment with a dynamic model. The idea of integrating fracturing with a dynamic model is shown in the Figure 4. Due to the possible interference of the wells, it is necessary to determine the distance between the horizontal parts of the trajectories providing the shale reservoir. In order to determine the distance between wells allowing to maximize the rate of depletion of resources located in the stimulated zone, a numerical algorithm based on the dynamic model was developed and implemented. The SRV zone along with the models is implemented in the reservoir simulator (Fig. 5) where, at the initial stage of operation, the volume of gas occurring in the assumed zone is estimated. In the next stage of the algorithm, the exploitation P1 and P2 wells is forecasted (the wells are assumed to work with the same production parameters). At the end of the simulation stage, the resource depletion rate in the SRV is estimated, if it has improved between successive iterations, the algorithm continues to operate to reach the minimum possible distance between the wells. To determine the minimum distance between holes, it is assumed that the maximum gap $x f$ is at least 50 meters from the second well. 


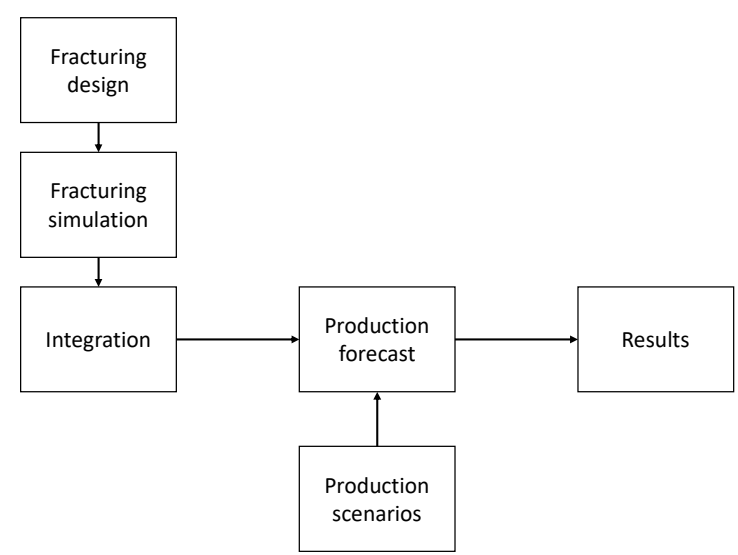

Fig. 4. Schematic diagram of the integration of fracture treatment with a reservoir simulator

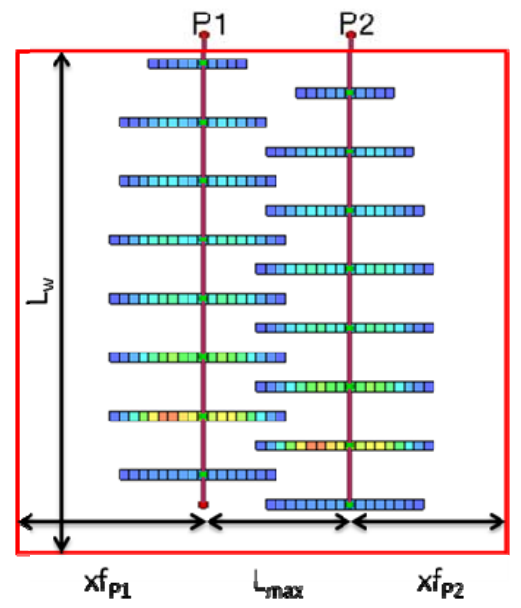

Fig. 5. SRV zone size

Numerical simulation of hydraulic fracturing was performed by utilisation of Guar 40\# treatment fluid, 30/50 mesh proppant size with maximum concentration of $400 \mathrm{~kg} / \mathrm{m}^{3}$. The assessment of efficiency of exploitation depending on the wells location was carried out where wells $\mathrm{P} 1$ and $\mathrm{P} 2$ are control by maximum pressure depression of 90 bar with limits of water production of $40 \mathrm{~m}^{3} / \mathrm{d}$ and $80 \mathrm{~m}^{3} / \mathrm{d}$ respectively for case A ( 8 fractures) and B (15 fractures).

\section{Results}

For variants involving the execution of 8 states fracturing, the recovery factor in the SRV zone is from $0.904 \%$ for a distance of $600 \mathrm{~m}$ to $1.168 \%$ for a distance of $300 \mathrm{~m}$. In case B (15 fractures) SRV recovery factor is $2.235 \%$ for a distance of $600 \mathrm{~m}$ to $2.949 \%$ for a distance of $300 \mathrm{~m}$. Results are presented in Figure 6. Extremly low matrix permeability of shales couses that depletion process takes places only in SRV zone (Fig. 7-10). Comparison of results reveal that for both cases (A and B) distance between wells is an inportant factor which have influence on SRV recovery factor. By getting well closer to each other, results can be improved from 5.50 to $29.75 \%$ (case A) or $32.50 \%$ (case B). 

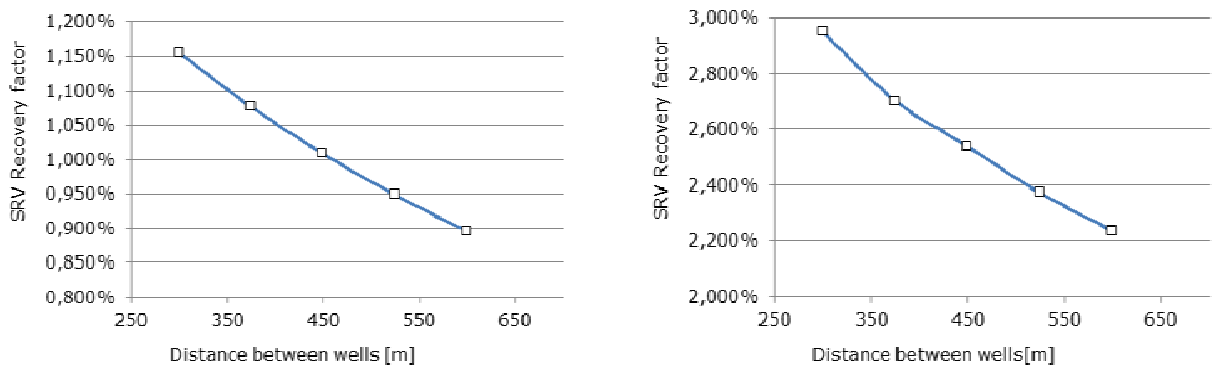

Fig. 6. Summary of the results of the recovery factor as a function of the distance between wells, for case A (left) and B (right)
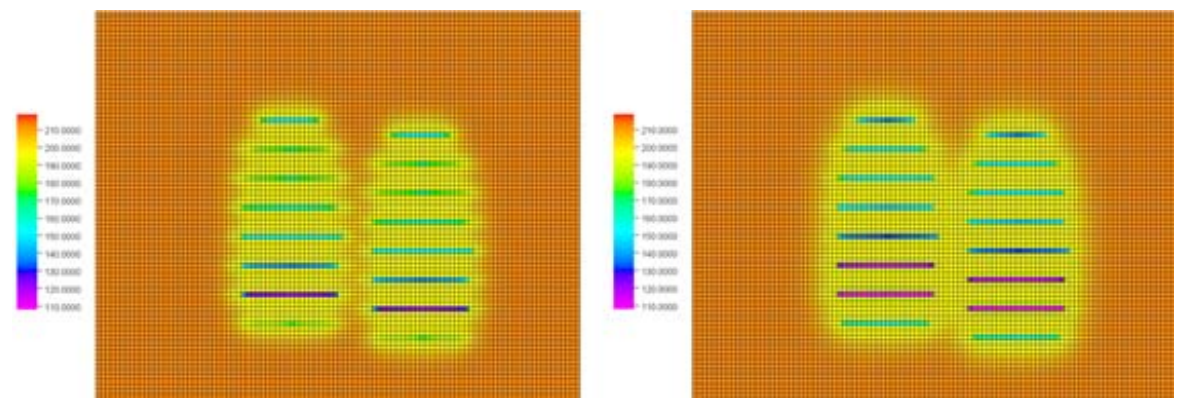

Fig. 7. Pressure distribution after 5 and 10 years of exploitation, case A ( 8 ftactures), $600 \mathrm{~m}$ distance between wells
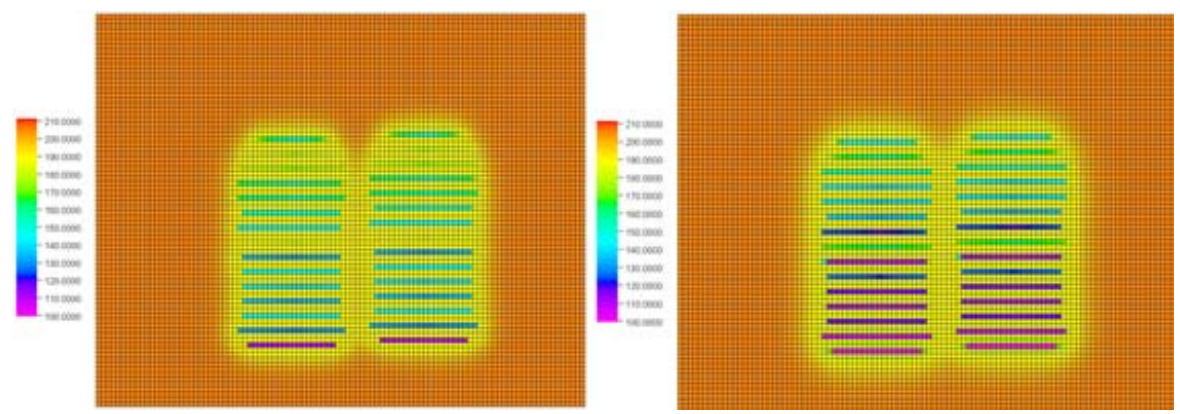

Fig. 8. Pressure distribution after 5 and 10 years of exploitation, case B ( 15 ftactures), $600 \mathrm{~m}$ distance between wells

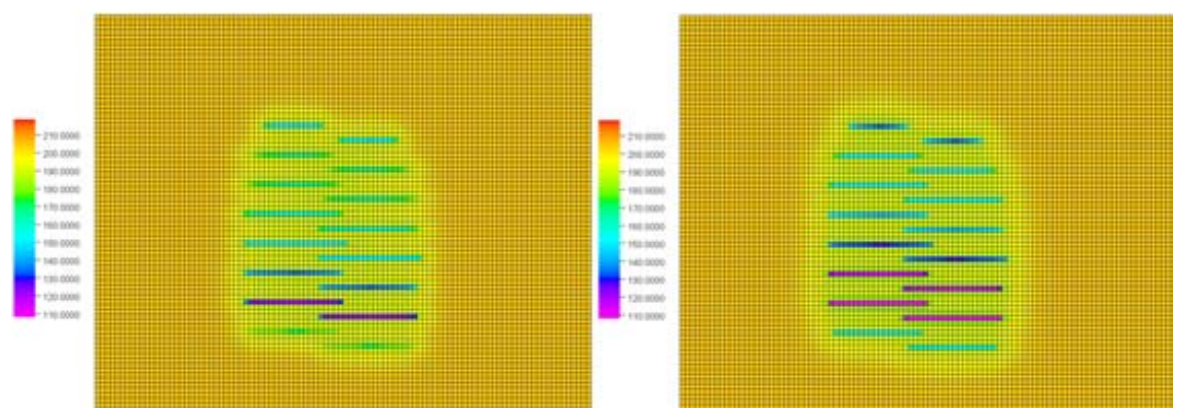

Fig. 9. Pressure distribution after 5 and 10 years of exploitation, case A ( $8 \mathrm{ftactures}), 300 \mathrm{~m}$ distance between wells 

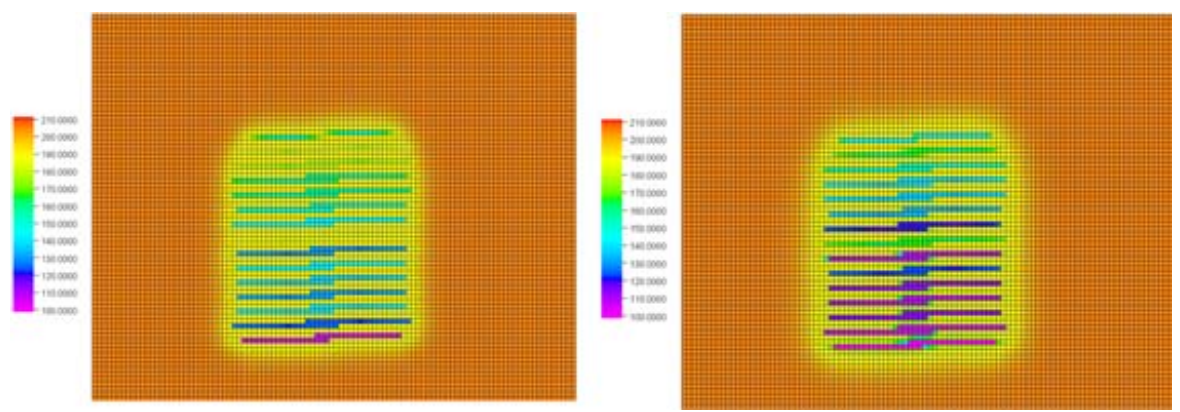

Fig. 10. Pressure distribution after 5 and 10 years of exploitation, case B (15 ftactures), $300 \mathrm{~m}$ distance between wells

Summary results are presented in Figure 11. Clusters of 15 perforation generates better results in comparition of 8 fractures due to better hydraulic connection (larger overal fracure area).

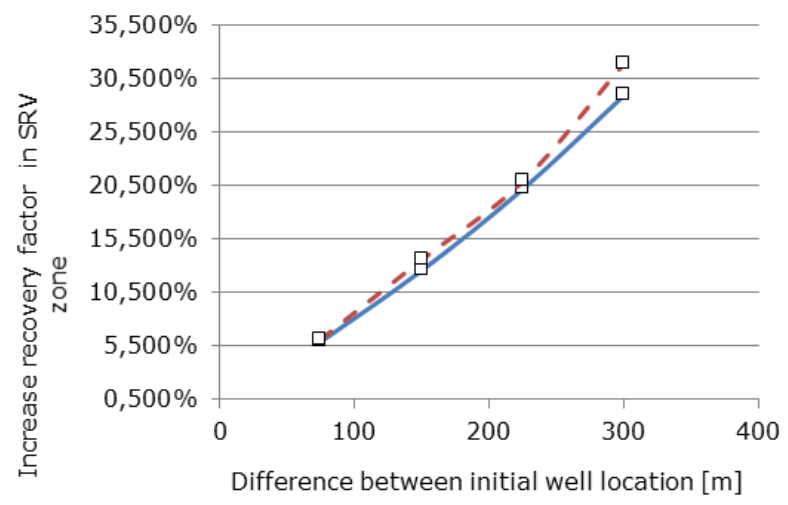

Fig. 11. Changes in the RSV recovery factor on relative to the initial position of the wells, continuous line - case A, dashed line case B

The cumulative output of natural gas in the assumed operating period was chosen as the measure of the effectiveness of the simulation. After 10 years of production for 8 fracture total gas production is over $45 \mathrm{mln} \mathrm{m}^{3}$ in comparition of over $63 \mathrm{mln} \mathrm{m}^{3}$ in case of 15 fractures. Results of total gas production is presented in Figure 12.

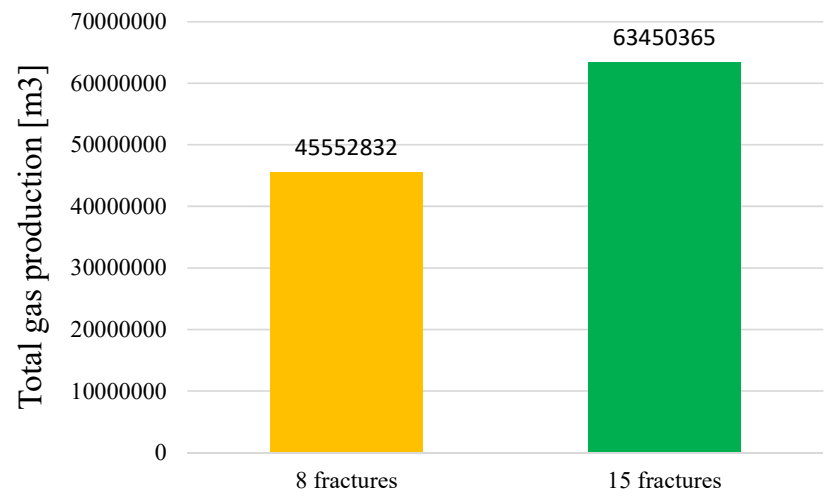

Fig. 12. Total gas production after 10 years of production 


\section{Conclusion}

Because of the low shale reservoir permeability, the fracturing procedure should be aimed at maximizing the hydraulic contact. Based on the analyzed scenarios, in terms of operation, cluster of 15 perforation formation allows over 1.5 times the increase in cumulative production compared to the 8 cluster. Due to the possible interference of wells, it is necessary to determine the effect of distances of stimulated wells on the recovery factor in SRV zone. With regard to the recoverable resources of the stimulated zone, the most advantageous arrangement assumes the minimum permissible distance between the wells. This is related to the ratio of the volume of the drainage zone to the total volume of the stimulated zone.

\section{References}

1. J. Stopa, P. Wojnarowski, D. Janiga, AGH Drilling, Oil and Gas, 31, (2014)

2. P. Valko, M.J. Economides, Hydraulic Fracture Mechanics, (1997)

3. T.H. Leshchyshyn, K.K. Deadall, P.E. Mayer, M.W. Hagel, B.R. Mayer, SPE International Thermal Operations and Heavy Oil Symposium and Western Regional Meeting, (2004)

4. L.H. Ribeiro, M.M. Sharma, SPE Annual Technical Conference and Exhibition, (2012)

5. J. Adachi, E. Siebrits, A. Peirce, J. Desroches, Journal of Rock Mechanics and Mining Sciences, 44, 739-757, (2007)

6. M.J. Economides, K.G Nolte, Reservoir Stimulation 3rd Edition, (2000)

7. D. Peng, D.B. Robinson, Industrial and Engineering Chemistry Fundamentals, 15, 5964, (1976)

8. I. Langmuir, Journal of the American Chemical Society, 38, 2221-2295, (1916)

9. H. Liu, Y. Luo, X. Li, Y. Xu, K. Yang, L. Mu, W. Zhao, W. Zhou, SPE Annual Technical Conference and Exhibition, (2012)

10. M Rafiee, M.Y. Soliman, E. Pirayesh, SPE Canadian Unconventional Resources Conference, (2012)

11. M Rafiee, M.Y. Soliman, E. Pirayesh, SPE Annual Technical Conference and Exhibition, (2012) 